\title{
PENGEMBANGAN MODUL PEMBELAJARAN KEWIRAUSAHAAN MODEL STUDENT COMPANY DI SMK NEGERI 1 GODEAN
}

\author{
Fetrika Anggraini \\ Pendidikan Ekonomi Fakultas Ekonomi Universitas Terbuka Bojonegoro \\ avetric@yahoo.co.id \\ Sukardi \\ Universitas Negeri Yogyakarta \\ sukardi1953@gmail.com
}

\begin{abstract}
Abstrak
Penelitian ini bertujuan untuk mengembangkan modul kewirausahaan model student company yang layak digunakan di SMK. Penelitian ini merupakan penelitian dan pengembangan. Hasil penelitian adalah sebagai berikut. (1) Modul pembelajaran kewirausahaan model student company layak digunakan. (2) Menurut siswa, modul yang dikembangkan berkualitas sangat baik, serta jika dilihat dari nilai skewnes distribusi data adalah normal. (3) Penerapan modul dalam proses pembelajaran secara umun dapat terlaksana. (4) Peningkatan pemahaman siswa dengan menggunakan modul yang dikembangkan berkategori sedang dengan rerata Uji-t sebesar 80,03 dan selisih nilai (effect size) 13,97 dengan persentase ketuntasan siswa sebesar 95\%. Pembelajaran menggunakan modul juga mampu melatih kemandirian siswa dalam belajar dan mampu menumbuhkan kemampuan dalam bekerjasama.
\end{abstract}

Kata kunci: pengembangan, modul, kewirausahaan, model student company

\section{THE DEVELOPMENT OF A STUDENT COMPANY MODEL OF ENTREPRENEURIAL LEARNING MODULE AT SMK NEGERI 1 GODEAN}

\begin{abstract}
This study aimed to develop a student company model of entrepreneurial learning module which was appropriate for SMK. This study was research and development. The results of the study were as follows. (1) The student company model of entrepreneurship learning module was appropriate for use. (2) According to the students, the developed module was excellent and the skewness of the data distribution was normal. (3) Generally, the implementation of the module in the learning process was succesful. (4) The increase of the students' understanding by using the developed module was in the fair category with an average t-test score of 80,3 and the difference in value (effect size) of 13,97 with students' mastery percentage of 95\%. The learning using the module was also able to train the students' autonomy in learning and able to improve the ability to cooperate.
\end{abstract}

Keywords: development, module, entrepreneurial learning, student company mode 


\section{PENDAHULUAN}

Pengangguran dan kemiskinan masih merupakan masalah besar yang dihadapi bangsa Indonesia sekarang ini, dan beberapa tahun ke depan. Jumlah pengangguran pada Februari 2014 hanya turun $0,12 \%$ dari $5,82 \%$ menjadi $5,70 \%$. Jumlah angkatan kerja pada Februari 2014 mencapai 125,3 juta orang, atau bertambah 1,7 juta orang dari Februari 2013. Sementara jumlah penduduk mencapai 118,2 juta orang atau bertambah 1,7 juta orang dari Februari 2013. Pencapaian TPT pada periode ini tercatat lambat atau menyusut sehingga mempersulit upaya penekanan angka pengangguran, kemiskinan ataupun ketimpangan pendapatan (BPS 2014).

Mc Clelland (Ciputra, 2008, p.37) menjelaskan bahwa untuk menjadi negara makmur suatu negara butuh entrepreneur (wirausaha) paling sedikit $2 \%$ dari jumlah penduduk. Indonesia hanya memiliki 400.000 entrepreneur atau sekitar $0,18 \%$ dari populasinya, sehingga Indonesia masih memerlukan 12 kali entrepreneur lebih banyak dari yang ada sekarang ini.

Pemerintah Indonesia selalu berupaya untuk meningkatkan kualitas sumber daya manusia (SDM) dengan berbagai inovasi pada program pendidikan ataupun pelatihan. Salah satu bentuk kesiapan dunia pendidikan dalam mengatasi situasi yang demikian adalah kemampuan dunia pendidikan membaca kebutuhan sumber daya manusia yang akan dihasilkan sesuai dengan kebutuhan pasar tenaga kerja. Sekolah Menengah Kejuruan (SMK) merupakan lembaga pendidikan yang berpotensi untuk mempersiapkan SDM yang dapat terserap oleh dunia kerja dan membuka usaha sendiri sebagai wirausaha (entrepreneur).

Berdasarkan hasil observasi awal di SMK Negeri 1 Godean ditemukan berbagai kendala dalam menerapkan proses pembelajaran kewirausahaan: (1) pembelajaran kewirausahaan hanya dilakukan secara konvensional, tanpa memberi pengalaman peserta didik agar berbuat secara aktif dalam belajar, sehingga siswa sering merasa jenuh terhadap materi yang dipelajarinya; (2) guru mengalami kesulitan untuk menentukan jenis kegiatan yang akan menggali aktivitas siswa pada pembelajaran kewirausahaan; (3) pembelajaran kewirausahaan ditetapkan pada silabus dengan jumlah tatap muka 2 jam/minggu, jumlah ini masih kurang untuk mata pelajaran kewirausahaan yang lebih mendalam; (4) bahan ajar atau materi ajar yang digunakan guru dalam pembelajaran masih terbatas, hal ini menjadikan pembelajaran kewirausahaan menjadi kurang menarik, sehingga peserta didik kurang termotivasi untuk belajar. $\mathrm{Ku}$ rangnya motivasi peserta didik dapat dilihat dari perhatian peserta didik yang masih kurang pada saat pembelajaran, dan sebagian peserta didik yang masih kurang fokus dalam memperhatikan penjelasan ataupun tugas yang diberikan guru.

Dalam meningkatkan kemampuan peserta didik dan mengembangkan kemampuan berpikir, maka diperlukan metode dan model pembelajaran yang tepat. Metode dan model pembelajaran kewirausahaan yang tepat untuk mengasah kognitif, afektif dan keterampilan psikomotor adalah simulasi student company. Metode simulasi adalah metode yang meragakan sesuatu dalam bentuk tiruan yang mirip dengan keadaan sesungguhnya. Metode simulasi yang diadaptasi dengan menggunakan model pembelajaran perusahaan siswa (student company) diperlukan sebagai wahana pelatihan peserta didik dalam memberikan pengalaman langsung pada sebuah kegiatan usaha, agar peserta didik dapat menjadi manusia yang mandiri.

Pendapat yang sama dinyatakan oleh Volkmann (2007, p.185) yang mengemukakan bahwa, "The key point is that one becomes an entrepreneur not by birth but by education as well as by experience". Titik kunci menjadi entrepreneur yang sukses bukanlah berasal dari faktor keturunan tetapi seorang entrepreneur juga bisa mencapai sukses melalui pendidikan dan pengalaman.

Berdasarkan uraian tersebut, perlu adanya suatu pengembangan bahan ajar yang sesuai dengan pembelajaran kewirausahaan di SMK. Bahan ajar yang paling tepat untuk dikembangkan adalah modul. Modul adalah suatu unit yang lengkap yang berdiri sendiri dan terdiri atas suatu rangkaian kegiatan belajar yang disusun untuk membantu peserta didik mencapai sejumlah tujuan yang dirumuskan secara khusus dan jelas (Nasution, 2010, p.205). Bahan ajar modul ini dipilih karena modul mampu mengatasi keterbatasan waktu, ruang, daya indera, baik siswa maupun guru. Selain itu, modul memungkinkan bagi 
peserta didik untuk belajar secara mandiri (independent).

Dengan dikembangkannya modul pembelajaran kewirausahaan yang disusun berdasarkan standar isi, maka diharapkan dapat menambah referensi untuk kegiatan pembelajaran kewirausahaan. Selain itu, modul yang dikembangkan diharapkan dapat menjadi salah satu contoh bagi para guru kewirausahaan dalam mengembangkan bahan ajar berupa modul. Modul yang dikembangkan oleh peneliti akan diimplementasikan dalam pembelajaran kewirausahaan di SMK Negeri 1 Godean untuk mengetahui kelayakan dan keefektifan modul yang dikembangkan tersebut.

\section{Pendidikan Kejuruan}

Clarke \& Winch (2008, p.63) mendefinisikan bahwa "Vocational Education is about the social development of labour, about nurturing, advancing, and reproducing particular qualities of labour to improve the productive capacity of society". Sejalan dengan pelaksanaan pendidikan yang merujuk pada UU Nomor 20 Tahun 2003 tentang tujuan utama pendidikan kejuruan yang mempersiapkan siswa untuk mandiri, mampu bekerja pada bidang tertentu, maka peran penyelenggaraan pendidikan kejuruan memberikan dampak positif pada pendidikan yang diharapkan dunia kerja, dan diharapkan dapat meningkatkan taraf hidupnya.

Selain itu Winch (2009, p.98) mengemukakan bahwa "Vocational education in Britain is usually regarded as skill training, in which ability to perform specific actions related to narrowly-defined tasks is the desired outcome. In Britain the term 'training' is more commonly used than 'vocational education". Pendidikan kejuruan di Inggris biasanya dianggap sebagai pelatihan keterampilan, yang kemampuan untuk melakukan keterampilan tugas didefinisikan sebagai hasil yang diinginkan dalam lapangan kerja. Di Inggris istilah "pelatihan" lebih sering digunakan dari pada "pendidikan kejuruan"

Beberapa pengertian tentang pendidikan kejuruan tersebu pada prinsipnya sama yaitu merupakan bagian dari sistem pendidikan yang mempersiapkan seorang agar siswa memiliki kamampuan bekerja pada satu kelompok pekerjaan atau satu bidang pekerjaan tertentu atau bidang-bidang lainya. Peran pendidikan kejuruan sangat penting dalam me- nyiapkan generasi yang terampil agar peserta didik siap kerja setelah lulus.

\section{Kewirausahaan}

Menurut Schumpeter (Alma, 2001, p.79) pengertian wirausaha adalah "Entrepreneur as the person who destroys the existing economic order by introducing new products and services, by creating new forms of organization, or by exploiting new raw materials. Wirausaha adalah orang yang mendobrak sistem ekonomi yang ada dengan memperkenalkan barang dan jasa yang baru, dengan menciptakan bentuk organisasi yang baru, atau mengolah bahan baku baru. Orang tersebut bisa melakukan kegiatannya melalui organisasi bisnis yang baru ataupun bisa pula dilakukan dalam organisasi yang sudah ada.

Hisrich \& Peter (Saiman, 2014, p.18), mengemukakan bahwa seorang entrepreneur adalah pelopor dalam bisnis, seseorang yang memiliki kepribadian yang kreatif, inovatif, produktif, disiplin, penanggung resiko yang mempunyai visi ke depan dan memiliki keunggulan dalam prestasi bidang usaha. Sedangkan Hunter (2013, p.56) mengemukakan bahwa,

Entrepreneurship is an individual or collective way of thinking, constructing an opportunity attached to a vision, which somehow precipitates the gathering, coopting, combining and organizing of resources into enactment upon the opportunity with the goal of activating the vision, utilizing knowledge, technology, and business tools in a relatively novel way to realize results, that have the possibility of creating a sustainable organization, where there are willing followers who share the vision.

Kewirausahaan adalah seseorang individu yang secara kolektif berpikir, membangun kesempatan pada visi dan misi, mencari kesempatan dengan tujuan sesuai dengan visi dengan mengembangkan pengetahuan, teknologi, dan alat-alat yang bisa digunakan untuk bisnis untuk menciptakan sebuah usaha baru. Menurut Hisrich (Alma, 2001, p.14) kewirausahaan yaitu sebagai berikut.

Entrepreneur is the process of creating something different with value by devoting the necessary time and effort, 
assuming the accompanying financial, psychological, and social risk and receiving the resulting reward of monetary and personal satisfaction.

Wirausaha merupakan proses penciptaan sesuatu yang berbeda dengan mengabdikan seluruh waktu dan tenaganya disertai dengan menanggung resiko keuangan, kejiwaan, sosial dan menerima balas jasa dalam bentuk uang dan kepuasan pribadinya.

Dari beberapa pendapat tersebut dapat disimpulkan bahwa kewirausahaan merupakan suatu kemampuan dalam hal menciptakan kegiatan usaha. Kemampuan menciptakan memerlukan adanya kreativitas dan inovasi yang terus menerus untuk menemukan sesuatu yang berbeda dari yang sudah ada sebelumnya.

\section{Simulasi}

Menurut Pusat Bahasa Depdiknas (2002) simulasi adalah satu metode pelatihan yang memperagakan sesuatu dalam bentuk tiruan (imakan) yang mirip dengan keadaan yang sesungguhnya; simulasi: penggambaran suatu sistem atau proses dengan peragaan memakai model statistik atau pemeran. C. Laroque. et.al. (2012, p.78) menyatakan bahwa, The simulations would place students in real-life situations, helping them to learn by doing and from their mistakes. Metode simulasi akan menempatkan siswa dalam situasi kehidupan nyata, membantu mereka untuk belajar sehingga mendapatkan pengalaman langsung dari hasil belajarnya tersebut. Vetro (2010, p.67) menyatakan bahwa, Simulations allow students to learn about the intricacies of interdependent complex systems by engaging in discourse with other students and teachers. Simulasi memungkinkan siswa untuk belajar tentang seluk-beluk sistem yang kompleks dan saling bergantung sehingga terlibat dalam wacana antara siswa dan guru. Simulasi memiliki potensi besar dalam meningkatkan pemahaman siswa dalam proses integrasi. Hal ini akan bermanfaat bagi siswa pada saat terjun ke masyarakat kelak karena ia mendapatkan diri dalam situasi yang banyak peran terjadi seperti di dunia kerja. Pendekatan simulasi dirancang agar mendekati kenyataan sehingga gerakan yang dianggap kompleks sengaja dikontrol, misalnya, dalam proses simulasi ini dilakukan dengan meng-gunakan simulator.

\section{Student Company atau Perusahaan Siswa}

Student Company atau perusahaan siswa adalah kegiatan ekstrakurikuler yang merupakan program aplikasi kewirausahaan bagi para siswa dengan diberikanya kesempatan untuk menjabat dan menjalankan operasional perusahaan. Student company adalah program penunjang yang bertujuan memberikan bekal bagi para siswa setingkat SMK atau SMA. Pemberian bekal yang ada dalam student company itu menjadi bekal yang berbentuk keterampilan serta semangat untuk dapat memiliki mental kemandirian. Para siswa dilatih untuk menjadi pemimpin perusahaan seperti direktur utama (CEO), direktur keuangan (CFO), dan posisi penting lainya.

Dengan begitu, siswa akan mempunyai bekal informasi bisnis seperti teori kepemimpinan, perencanaan bisnis, proses pengambilan keputusan, studi pasar dan implementasinya. Indikator atau target yang ingin dicapai dalam program student company adalah: (1) tumbuhnya semangat berwirausaha di kalangan pelajar; (2) siswa siap dan mampu dalam suatu usaha sederhana yang akan dibentuk sebagai inti dari student company dan usaha yang dibentuk bisa merupakan usaha bersama atau usaha mandiri; (3) tumbuhnya jiwa wirausaha pada siswa.

\section{Modul}

Modul merupakan jenis kesatuan kegiatan belajar yang terencana, dirancang untuk membantu peserta didik secara individual dalam mencapai tujuan-tujuan pembelajaranya. Modul bisa dipandang sebagai paket program pembelajaran yang terdiri dari komponen-komponen atau media, serta sumber belajar dan sistem evaluasinya (Sudjana dan Rifai, 2007, p.132). Menurut Goldschmid (1996, p.68) dalam Sukiman "Module as a self-contained, independent unit of a plenned series of lesrning activities designed to help the student accomplish certain well defined".

Modul sebagai jenis satuan kegiatan belajar yang terencana, didesain guna membantu siswa menyelesaikan tujuan-tujuan tertentu. Meyer (1978, p.2) mendefinisikan bahwa modul adalah sebagai berikut. 
A module is a relatively short self-contained, independent unit of instruction designed to achive a limited set of specific and well-defined educational $o b$ jectives. It usually has a tangible format as a set or kit of co-ordinated and highly produced materials involving a variety of media. A module may or may not be designed for individual self paced learning and may employ a variety of teaching teachnique.

Modul adalah suatu unit desain pembelajaran yang isinya relatif singkat dan spesifik, yang disusun untuk mencapai tujuan pembelajaran. Modul biasanya memiliki suatu rangkaian kegiatan yang terkoordinasi dengan baik berkaitan dengan materi dan media serta evaluasi. Modul dapat digunakan secara individual dan dapat pula digunakan dalam kelompok seperti kelas. Modul berisi tujuan pembelajaran yang ingin dicapai melalui kegiatan belajar, materi yang berisi bahan ajar, media yang digunakan dan langkah pembelajaran serta evaluasi.

Dari uraian tersebut dapat ditarik kesimpulan bahwa modul merupakan suatu unit bahan ajar yang dirancang secara khusus sehingga dapat dipelajari oleh perserta didik secara mandiri, selain itu modul merupakan program pembelajaran yang utuh, disusun secara sistematis yang mengacu pada tujuan pembelajaran atau kompetensi yang jelas dan terukur. Modul memuat tujuan pembelajaran, bahan dan kegiatan untuk mencapai tujuan serta alat evaluasi terhadap pencapaian tujuan pembelajaran daan modul bisa digunakan sebagai bahan ajar mandiri pada sistem pendidikan.

\section{Metode Pengembangan}

Model pengembangan yang digunakan mengacu pada model 4-D (Thiagarajan, Semmel \& Semmel, 1974) yang terdiri dari 4 tahap, yaitu Define (pendefinisian) meliputi prapenelitian, analisis siswa, analisis konsep, analisis tugas, dan perumusan tujuan pembelajaran, Design (perancangan) meliputi pemilihan media, pemilihan format, desain awal modul, Develop (pengembangan) meliputi, validasi ahli, uji coba dengan siswa, dan Disseminate (penyebaran).

Penelitian pengembangan dilakukan di SMK Negeri 1 Godean. Kelayakan diketahui melalui uji coba. Uji coba modul dilakukan dengan uji coba kelompok kecil/terbatas dan uji coba lapangan di SMK N 1 Godean. Uji coba kelompok kecil/terbatas dilakukan untuk kelas kecil dengan jumlah siswa 10 orang yang dipilih secara acak. Hasil dari uji coba kelompok kecil/terbatas dijadikan masukan untuk perbaikan modul yang akan digunakan pada uji coba lapangan. Kelas ujicoba lapangan terdiri dari 64 siswa. Instrumen pengumpulan data menggunakan angket, lembar observasi dan tes. Teknik analisis data menggunakan skala empat dan statistik deskriptif.

\section{HASIL PENELITIAN}

Keterlaksanaan modul pembelajaran hasil pengembangan dalam pembelajaran secara sistematis tertuang dalam rencana pelaksanaan pembelajaran (RPP). Rencana pelaksanaan pembelajaran menggunakan produk ini dilakukan selama tiga kali pertemuan. Pertemuan pertama dilaksanakan pada tanggal 2 April 2015, pertemuan kedua pada tanggal 6 April 2015, dan pertemuan ketiga pada tanggal 9 April 2015. Keterlaksanaan RPP untuk pertemuan pertama, pertemuan kedua, dan pertemuan ketiga rata-ratanya 100,0.

Respon siswa terhadap modul kewirausahaan hasil pengembangan ini dari aspek materi mendapatkan skor total 13,17 , dari aspek keterbacaan bahasa dan gambar mendapatkan skor total 18,87 , dari aspek penyajian mendapatkan skor total 48,10 dan dari aspek tampilan mendapatkan skor 18,41 . Keempat aspek mendapatkan nilai A dengan kategori "sangat baik".

Berdasarkan data yang diperoleh pada uji lapangan diketahui bahwa dalam kegiatan pembelajaran berbasis proses terdapat beberapa temuan. Temuan-temuan tersebut menjadi sebuah masukan bagi guru dalam memperbaiki proses pembelajaran yang baik agar siswa lebih dapat memperhatikan pelajaran, namun dengan ditemukan temuan tersebut diketahui bahwa orientasi pada pembelajaran sangat berpengaruh terhadap hasil belajar siswa.

Berdasarkan data yang diperoleh diketahui bahwa modul kewirausahaan mampu menaikkan rerata nilai post-test terhadap nilai pre-test (dari rerata 66,06 menjadi 80,03 ada kenaikan rerata post-test terhadap rerata nilai pre-test sebesar 13,97 dan nilai tersebut me- 
rupakan nilai kebermaknaan siswa (effect size) ketika belajar menggunakan modul hasil pengembangan. Hal ini membuktikan terjadinya peningkatan pemahaman siswa tentang materi kerajinan. Dengan kata lain, ada kebermaknaan belajar menggunakan modul. Apabila kriteria ketuntasan minimal belajar adalah 70 , maka 95\% siswa yang telah tuntas belajar. Jika ditinjau dari perhitungan uji-t maka pembelajaran pada uji coba kelompok kecil meningkatkan hasil belajar siswa dengan kategori sedang.

Hasil penilaian terhadap hasil belajar afektif siswa yang terdiri dari "kemampuan siswa bekerja sama antaranggota kelompok" dan "kemampuan siswa belajar mandiri" didapatkan rerata nilai 76,06. Apabila kriteria ketuntasan minimal belajar adalah 70 , maka 95\% siswa yang telah tuntas belajar. Artinya, siswa telah tuntas dalam bekerja sama dan tuntas dalam belajar mandiri. Hasil belajar priskomor dinilai dari kinerja siswa dalam melakukan kegiatan praktik didapatkan rerata nilai 76,21. Artinya, siswa telah tuntas belajar dari aspek psikomotor.

\section{SIMPULAN DAN SARAN}

\section{Simpulan}

Produk modul yang dibutuhkan mata pelajaran kewirausahaan di SMK yakni modul yang dapat mengatasi keterbatasan waktu, ruang, menarik, meningkatkan kemampuan siswa, dan dapat meningkatkan kemandirian siswa dalam belajar. Kualitas modul ditinjau dari aspek kelayakan isi, aspek bahasa dan gambar mendapatkan tanggapan yang positif dan layak dengan kategori baik.

Berdasarkan hasil analisis data respon siswa terhadap modul pembelajaran, diketahui bahwa modul pembelajaran dalam kategori "Sangat Baik". Jika dilihat dari nilai skewness distribusi data adalah normal dengan kemiringan berada di kiri atau negatif, sehingga modul harus dipertahankan dan digunakan sebagai salah satu sumber bahan ajar karena mudah dipahami dan diterima oleh siswa.

Berdasarkan hasil analisi data penerapan modul dalam pembelajaran secara umum dapat terlaksana. Hal ini dibuktikan dengan hasil keterlaksanaan rencana pembelajaran pada pertemuan pertama, kedua, dan ketiga mencapai presentase keterlaksanaan sebesar $100 \%$.

Modul pembelajaran meningkatkan rerata skor pemahaman siswa (effect size= 13,97) dan $95 \%$ siswa mencapai ketuntasan belajar. Peningkatan hasil belajar dihitung menggunakan uji-t.

\section{Saran}

Modul yang dihasilkan ini dapat dimanfaatkan sebagai salah satu penunjang bahan ajar yang sudah ada. Modul ini sebaiknya dipertahankan dan digunakan karena berdasarkan respon siswa yang sangat baik dan hasil belajar siswa menjadi meningkat stelah menggunakan modul. Penerapan modul pembelajaran perlu dikembangkan lagi, sehingga siswa dapat mencapai kompetensi yang diharapkan. Oleh karena itu, guru prakarya dan kewirausahaan diharapkan mampu memanfaatkan dan mengembangkan bahan ajar yang lain sebagai alternatif agar siswa dapat terlibat aktif dalam pembelajaran sekaligus dapat lebih mudah dalam memahami materi pembelajaran.

\section{DAFTAR PUSTAKA}

Alma, B. (2001). Kewirausahaan. Bandung: Alfabeta.

Badan Pusat Statistika. (2014). Tingkat pengangguran terbuka februari 2014. Diakses tanggal 10 Juni 2014 dari http://www.bps.go.id/brs/view/id/1139.

Ciputra. 2008. Quantum leap: bagaimana entrepreneurship dapat mengubah masa depan anda dan masa depan bangsa. Jakarta: PT Elex Media.

Clarke, L., \& Winch, C. (2008). Vocational education: International approaches, developments and systems. Madison Avenue, New York. Routledge Taylor $\&$ Francis Group, an informa business.

C. Laroque.et.al.(2012). An Investigation of The Use of Simulation Tools In Management Education. Proceeding of the 2012 Winter Simulation Cinference. Diakses dari: http://www.openscout. net. Pada tanggal 10 Juni 2015.

Hunter, M. (2013). A Typology of Entrepreneurial Opportunity. Journal 
Economics, Management, and Financial Markets. Vol.8, No.2, 2013, pp. 128-166.

Meyer, R. (1978). Designing Learning Modules for inservice Teacher Education. Australia: Centre for Advancement of Teaching.

Nasution. (2010). Berbagai pendekatan dalam proses belajar mengajar. Jakarta: PT. Bumi Aksara.

Pusat Bahasa Depdiknas. (2002). Kamus besar bahasa indoenesia. Jakarta: Balai Pustaka.

Sudjana, M., \& Rivai, A. (22070. Teknologi pengajaran. Bandung: Sinar Baru Algensindo.

Sukiman. (2012). Pengembangan media pembelajaran. Yogyakarta: Pedagogia.
Vetro. (2010). A collective simulation for teaching health science. Computer Supported Collaborative Learning. Vol. 5, 2010. Diakses dari: DOI 10.1007/s11412-010-9082-8. Pada tanggal 10 Juni 2015.

Volkmann, C. (2008) Entreprenurial studies in higher education. Journal of Higher Education Europe, Vol. 29, No 2, Jully 2004.

Winch, C. (2009). Ryle on Knowing How and the Possibility of Vocational Education. Journal of Applied Philoshopy. Vol. 26, No. 1, 2009.

Thiagarajan, S., Semmel, D.S \& Semmel, M.L (1974). Instructional development for training teacher of exeptional childre. Minnesota: Indiana University. 